\title{
RANCANG BANGUN SIMULATOR KONTROL LAMPU RAMBU LALU LINTAS BERBASIS PLC OMRON CPM1A
}

\author{
Ketut Udy Ariawan \\ Jurusan Teknik Elektronika, FTK, Universitas Pendidikan Ganesha, \\ Singaraja, Indonesia \\ email: udyariawan@yahoo.com
}

\begin{abstract}
Abstrak
Seiring dengan permasalahan arus lalu lintas / kemacetan di jalan raya khususnya di kota-kota besar Indonesia maka penulis mencoba merancang sistem simulasi lampu rambu lalu lintas yang berbasis PLC Omron CPM1A dengan menggunakan sensor kepadatan atau sering disebut Traffic Actuated Signal, untuk mengurangi kepadatan arus lalu lintas di kota-kota besar di Indonesia. Proses simulasi rambu lampu lalu lintas yang berbasis PLC Omron CPM1A menggunakan dua sistem kerja yaitu: sistem manual dan sistem otomatis. Dimana sistem manual bekerja dengan menggunakan waktu (timer) yang sudah ditentukan, sedangkan sistem otomatis bekerja dengan menggunakan sensor, sensor bekerja bila suatu kendaraan melintasi sensor tersebut dengan selang waktu 40 detik. Pada rancang bangun simulator lampu rambu lalu lintas berbasis PLC Omron CPM1A hasil simulasi baik itu pengukuran tegangan input atau output dan pengukuran arus input atau output sesuai dengan sistem alat yang dibuat. Tingkat kegagalan pada sistem alat sensor yang diuji $1 / 12 \times 100 \%=8,33 \%$, sedangkan tingkat keberhasilan alat sensor yang diuji $11 / 12 \times 100 \%=91,66 \%$. Kinerja sistem rancang bangun simulator lampu rambu lalu lintas berbasis PLC Omron CPM1A sangat dipengaruhi oleh tingkat sensitivitas dari sensor yang digunakan, oleh karena itu sensor yang digunakan sebaiknya sensor yang mendeteksi bahan logam seperti kendaraan umum.
\end{abstract}

Kata kunci: PLC, sensor, lampu rambu lalu lintas.

\begin{abstract}
Along with the problems of traffic flow / congestion on the highway, especially in big cities of Indonesia the author tries to design a system simulation traffic lights signs based Omron PLC CPM1A using a sensor density is often called Actuated Traffic Signal, in order to reduce the current density and traffic in big cities in Indonesia. Process simulation signs traffic lights based Omron PLC CPM1A uses two working systems, namely: the manual system and automated system. Where is the manual system works by using time that have been determined, while the automatic system works by using a sensor, the sensor works when a vehicle crosses the sensor with an interval of 40 seconds. In the design and construction of traffic sign simulator based Omron PLC CPM1A simulation results either input or output voltage measurement and current measurement inputs or outputs according to the system tools made. The failure rate of the system sensors were tested $1 / 12 \times 100 \%=8.33 \%$, while the success rate sensors were tested $11 / 12 \times 100 \%=$ $91.66 \%$. The performance simulator system design of traffic signs based Omron PLC CPM1A strongly influenced by the level of sensitivity of the sensor is used, therefore the sensor used should sensors detect metals such as public transport.
\end{abstract}

Keywords: PLC, sensors, traffic light signs. 


\section{PENDAHULUAN}

Seiring dengan permasalahan arus lalu lintas di jalan raya khususnya di kotakota besar Indonesia berkembang sangat pesat, dengan menyangkut beberapa faktor antara lain: faktor manusia, faktor jalan, serta faktor lingkungan. Kemacetan lalu lintas pun sering terjadi dipersimpangan jalan ataupun perempatan jalan. Pada persimpangan / perempatan jalan volume kendaraan tidak sama antara satu dengan yang lainnya.

Dikota - kota besar di Indonesia baik dipersimpangan jalan maupun diperempatan jalan lampu rambu-rambu lalu lintas kebanyakan menggunakan mikrokontroler dengan menggunakan sistem waktu atau sering kita sebut Pretimed Traffic Signal yaitu: urutan sinyal yang berulang-ulang secara teratur yang dihasilkan menggunakan program waktu yang ditentukan.

Penyalaan lampu rambu lalu lintas dengan sistem mikrokontroler / Pretimed Traffic Signal khususnya di kota-kota besar di Indonesia tidak efisien lagi. Karena waktu yang ditentukan tidak sebanding dengan kepadatan arus lalu lintas yang semakin lama semakin bertambah terus di sebuah persimpangan / perempatan jalan di kota besar Indonesia.

Oleh sebab itu dibuat sistem simulasi lampu rambu lalu lintas yang berbasis PLC Omron CPM1A dengan menggunakan sensor kepadatan. Rancang Bangun Simulator Lampu Rambu Lalu Lintas berbasis PLC Omron CPM1A dengan menggunakan sensor kepadatan diaplikasikan pada sebuah perempatan jalan. Disini sensor bekerja mendeteksi kepadatan arus lalu lintas disetiap perempatan jalan, dengan tujuan mengurangi kepadatan arus lalu lintas yang ada di perempatan jalan sehingga kepadatan arus lalu lintas akan berkurang dengan sendirinya.

\section{METODE}

Metode yang digunakan di dalam penelitian ini adalah metode penelitian tindakan yaitu penelitian yang dilaksanakan melalui tahap-tahap yang bertujuan untuk mencari dan membuat pemecahan masalah yang ada.

\section{Langkah-langkah Perancangan}

Agar penelitian ini mencapai sasaran yang diharapkan, maka dirumuskan langkah-langkah perancangan sebagai salah satu tahap dalam pembuatan suatu proses komponen yang penting dalam aplikasinya sebagai berikut:

1. Perancangan perangkat keras (hardware) yaitu meliputi merancang sistem kontrol PLC Omron CPM1A, sensor, relay, lampu indikator, limit switch, dan power supply.

2. Perancangan perangkat lunak (software) yang meliputi pemograman untuk PLC Omron CPM1A.

3. Pembuatan bagian-bagian mekanik yang berupa panel kontrol dan penempatan indikator.

\section{Diagram Alir Pengerjaan}

Dalam perancangan dan pembuatan simulasi pengaturan lampu rambu lalu lintas dengan PLC Omron CPM1A terdapat beberapa tahapan yang harus dilaksanakan seperti blok diagram dibawah ini: 


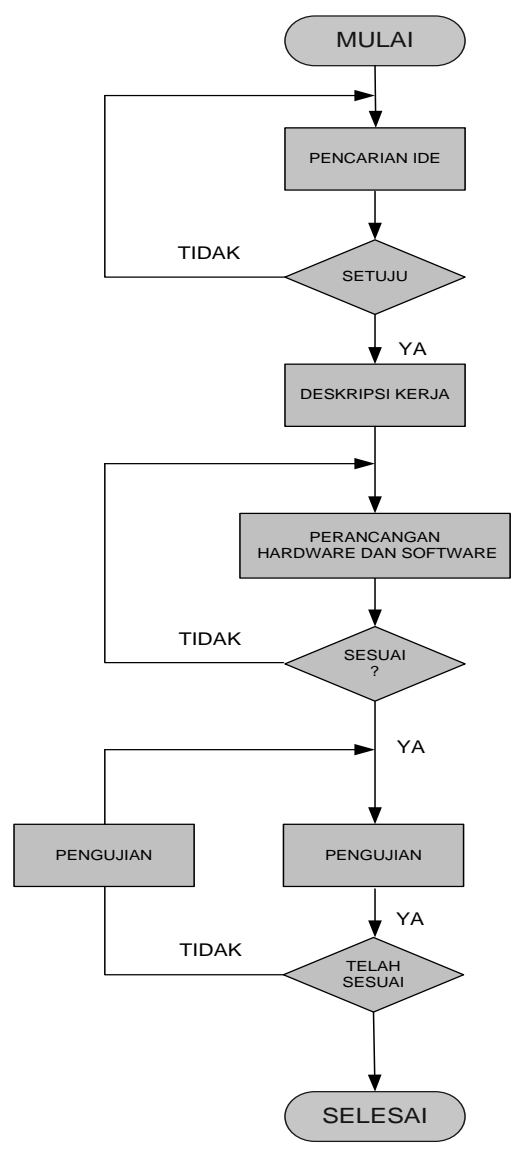

\section{Aplikasi Komponen Elektronika}

Komponen Utama

1. PLC

PLC yang digunakan adalah PLC jenis Omron Tipe Sysmac CPM1A Type CPU, PLC ini mempunyai versi tegangan kerja CPU Input $24 \mathrm{~V}$ DC Output 24 V DC dan 250 V AC Feature utama CPM1A-30 I/O, antara lain 18 input biner 12 output biner.

2. Lampu Indikator

Lampu indikator yang digunakan pada simulasi ini adalah lampu AC 220 Volt, yang terdiri dari 3 warna yaitu merah, kuning, dan hijau yang berfungsi sebagai pengatur lampu rambu lalu lintas sesuai dengan fungsinya masing-masing.

3. Relay

Relay yang digunakan jenis Relay Omron type MY2NJ Spec 5A 240 Volt $A C$ dan $5 A 28$ Volt DC yang berfungsi sebagai saklar yang bekerja berdasarkan elektromagnetis. Pemberi energi elektromagnetis yang berfungsi untuk membuka atau menutup pada rangkaian, relay biasanya mempunyai satu kumparan, tetapi relay dapat mempunyai beberapa kontak diantaranya memiliki kontak NO (Normaly Open) dan NC (Normally Close).

4. Rangkaian Sensor

Rangkaian Sensor yang digunakan yaitu jenis Sensor Ultrasonik yang diproduksi oleh TULUS KIT dengan tegangan 9 Volt sampai 12 Volt DC yaitu digunakan untuk mendeteksi daerah kepadatan pada persimpangan / perempatan suatu jalan.

Alat-alat ukur yang digunakan:

1. Voltmeter (DC)

Digunakan untuk mengukur besarnya nilai tegangan, antara lain:

a. Tegangan Power supply untuk Lampu Indikator

b. Tegangan Power supply untuk Sensor Ultrasonik

c. Tegangan pada Relay

d. Tegangan pada PLC

2. Amperemeter (AC)

Digunakan untuk mengukur besarnya nilai arus, antara lain:

a. Arus keluaran Lampu Indikator

b. Arus pada sensor Ultrasonik

c. Arus keluaran pada Relay

d. Arus keluaran pada PLC 


\section{Uji Coba}

Uji coba yang dilakukan dibagi dalam dua pengujian yaitu pengujian pada perangkat lunak yaitu meliputi:

1. Uji coba dalam rangkaian, bertujuan mencari kesalahan.

2. Uji coba benda, bertujuan untuk mencari kesalahan sebanyak mungkin yang akan terjadi pada sistem.

3. Uji coba berhasil, bertujuan menemukan kesalahan yang sebelumnya tidak akan terduga.

\section{Penggabungan Perangkat}

Setelah pengujian perangkat keras dan perangkat lunak selanjutnya adalah penggabungan perangkat keras (hardware) dan perangkat lunak (software). Langkah ini bertujuan untuk menyempurnakan sistem yang telah dirancang dan sesuai dengan yang diharapkan.

\section{Analisis Sistem}

Tahapan ini merupakan tahap untuk mengevaluasi kembali terhadap semua tahapan penelitian yang dilakukan dan menganalisis hasil yang dicapai, yang menjadi sasaran dalam penelitian ini. Tahap ini diharapkan akan lebih memudahkan di dalam penarikan kesimpulan.

HASIL DAN PEMBAHASAN

\section{Deskripsi Kerja Sistem tanpa Menggunakan Sensor}

Pada simulasi sistem lampu rambu lalu lintas ini terbagi menjadi 4 group dengan alamat output-nya yaitu:

1. Group I (lampu 1)
a. Lampu Hijau dengan alamat output: 10.05
b. Lampu Kuning dengan alamat output: 10.04
c. Lampu Merah dengan alamat output: 10.03

2. Group II (lampu 2)
a. Lampu Hijau dengan alamat output: 11.00
b. Lampu Kuning dengan alamat output: 10.07
c. Lampu Merah dengan alamat output: 10.06

3. Group III (lampu 3)
a. Lampu Hijau dengan alamat output: 11.03
b. Lampu Kuning dengan alamat output: 11.02
c. Lampu Merah dengan alamat output: 11.01

4. Group IV (lampu 4)

a. Lampu Hijau dengan alamat
output: 10.02
b. Lampu Kuning dengan alamat
output: 10.01
c. Lampu Merah dengan alamat
output: 10.00
Pada sistem simulasi lampu rambu lalu lintas ini akan diterangkan cara kerja lampu tersebut berdasarkan group dengan waktu yang berbeda. Jika lampu 1 hijau on dengan waktu 100 detik, maka lampu 3,4,2 merah akan on dengan waktu 110 detik, 220 detik, 330 detik, sedangkan jika lampu 1 kuning on dengan waktu 10 detik maka lampu 2,3,4 merah masih tetap merah dengan waktu yang sama. Sedangkan jika lampu 1 merah on 330 detik, maka lampu 3 hijau akan on dengan waktu 100 detik dan lampu 4,2 merah masih on dengan waktu 110 detik, 220 detik. Jika lampu 3 kuning on dengan waktu 10 detik, maka lampu 4,2,1 merah masih akan on dengan lama waktu yang sama. Sedangkan jika lampu 4 hijau on dengan lamanya waktu 100 detik, maka lampu 2,1,3 merah akan on dengan lamanya waktu 110 detik, 220 detik, 330 
detik. Sedangkan jika lampu 4 kuning on dengan lamanya waktu 10 detik, maka lampu 3,2,1 merah masih akan tetap on dengan lamanya waktu yang masih sama, dan jika lampu 4 merah on dengan lamanya waktu 110 detik, maka lampu 2 hijau akan on dengan lamanya waktu 100 detik dan lampu 3,1 merah masih tetap on dengan lamanya waktu 220 detik, 110 detik, sedangkan jika lampu 2 kuning on dengan lamanya waktu 10 detik, maka lampu 4,3,1 merah masih akan tetap on, dan jika lampu 2 merah on dengan lamanya waktu 330 detik maka lampu 1 hijau akan on dengan lamanya waktu 100 detik dan lampu 3,4 merah akan tetap on dengan lamanya waktu 110 detik, 220 detik, dengan skema berulang - ulang.

Pada sistem simulasi traffic light ini lampu merah dan lampu kuning diberi waktu yang sama (konstan) antara lampu yamg satu dengan yang lainnya, sedangkan lampu merah pada sistem traffic light ini diberi waktu yang berbeda antara lampu satu dengan lampu yang lainnya dengan maksud agar tidak terjadi bentrokan waktu pada lampu yang lainnya. Pada simulasi lampu rambu lalu lintas ini lampu kuning sengaja diberi waktu yang singkat sekali karena lampu kuning pada lampu rambu lalu lintas diberikan untuk jarak lampu hijau untuk memasuki ke lampu merah, jadi lampu kuning sengaja diberi waktu yang sangat singkat.

\section{Deskripsi Kerja Sistem dengan Menggunakan Sensor}

Pada simulasi sistem rambu rambul lalu lintas dengan sistem kerja sensor ini terdapat juga 4 group dengan alamat outputnya seperti terlihat pada deskripsi kerja sistem tanpa sensor. Dalam simulasi ini sensor bekerja bila ada benda atau kendaraan yang melintasi sensor tersebut. Bila jalur satu terjadi kepadatan atau banyaknya kendaraan yang melintasi sensor 1, maka sensor 1 akan bekerja dan otomatis lampu 1 hijau akan menyala dengan sendirinya. Sedangkan apabila pada jalur dua terjadi kepadatan maka sensor pada jalur 2 akan bekerja dan lampu hijau 2 akan menyala (ON) dan lampu merah 1 akan ON. Sedangkan apabila terjadi kepadatan yang sama disuatu perempatan maka dalam simulasi ini yang bekerja pertama adalah sensor 1 pada jalur 1 dengan dibantu oleh timer (waktu), sehingga kepadatan kendaraan Ialu lintas pada perempatan jalan dapat berkurang secara bergiliran dan tidak menimbulkan kemacetan yang panjang.

\section{Rancangan Simulator}

Komponen yang digunakan adalah komponen yang mempunyai persamaan fungsi dengan alat yang sebenarnya. Komponen yang digunakan mempunyai dimensi dan ukuran yang kecil sehingga simulator dapat dibuat dengan ukuran yang tidak terlalu besar. Berikut adalah gambar rancangan serta tata letak komponen:

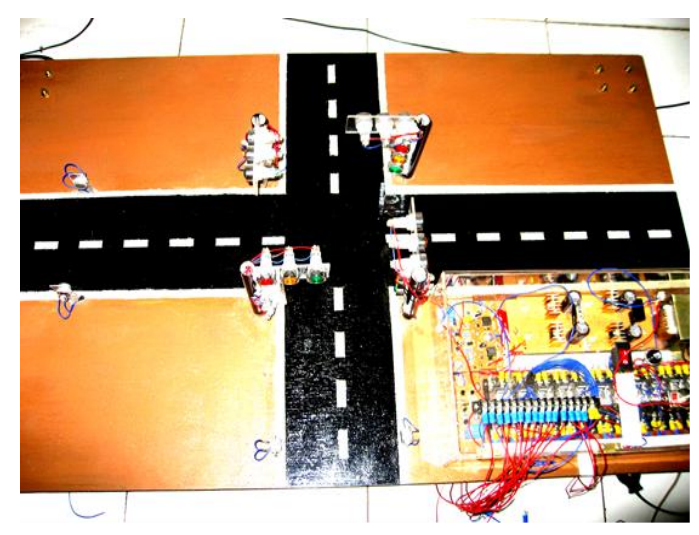

Jurnal Sains dan Teknologi| 39 


\section{Pengujian Perangkat Keras}

Pengujian perangkat keras ini dilakukan setelah proses perancangan dan pembuatan simulator selesai. Pengujian disini dilakukan dengan mengadakan pengukuran pada terminal input dan juga pengukuran pada terminal output dengan menghubungkan terminal com ke setiap terminal output maupun pengujian pada relay, catu daya, sensor ultrasonic, dan lampu indikator.
1. Pengujian Input

Pengujian input ini dilakukan dengan pengujian pada limit switch / auto, dan sensor ultrasonic yang terdapat pada simulasi. Data tersebut diambil dari hasil pengukuran langsung pada komponen simulator untuk mengetahui tegangan input yang dipakai. Dimana hasil yang di dapat sesuai dengan sumber tegangan yang diberikan yaitu 24 VDC. Untuk pengujian limit switch / auto dan sensor ultrasonik (SO) dilakukan dengan pengamatan pada simulator.

Tabel 1: Pengujian Sensor Ultrasonik (SO) dan Limit Switch / Auto

\begin{tabular}{|c|c|c|}
\hline Aksi & Reaksi & Hasil \\
\hline $\begin{array}{ll}- & \text { Sistem } \\
\text { Manual } \\
\text { (tanpa } \\
\text { sensor) }\end{array}$ & $\begin{array}{l}\text { - } \text { Auto } 1 \text { on } \\
\text { - } \quad \text { Lampu } 1 \text { hijau on selama } 100 \text { detik } \\
\text { - Lampu } 3 \text { hijau on selama } 100 \text { detik } \\
\text { - } \quad \text { setelah lampu } 1 \text { hijau off. } \\
\text { - } \quad \text { setelah lampu } 4 \text { hijau off. } \\
\text { - Lampu } 2 \text { hijau on selama } 100 \text { detik } \\
\text { setelah lampu } 4 \text { hijau off }\end{array}$ & Sesuai \\
\hline $\begin{array}{ll} & \text { Sistem } \\
\text { Otomatis } \\
\text { (dengan } \\
\text { sensor) }\end{array}$ & 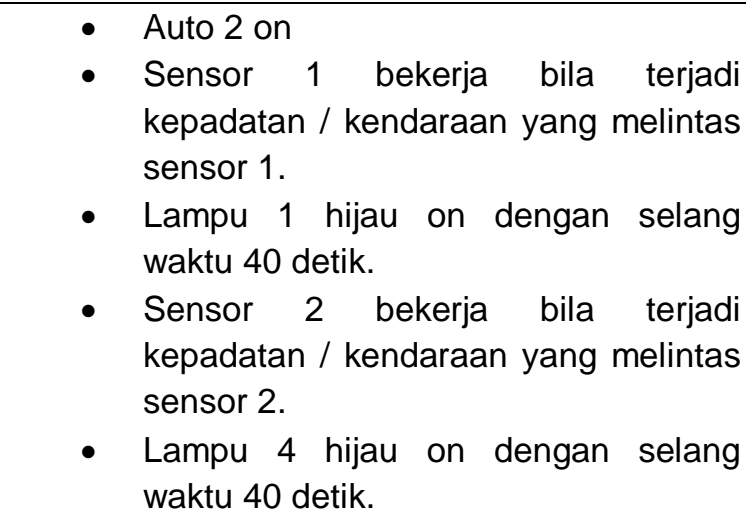 & Sesuai \\
\hline
\end{tabular}

*Sesuai: sesuai dengan kebenaran alat yang diuji 
2. Pengujian Output

Pengujian output dilakukan dengan mengamati kerja komponen pada saat terminal output yang dihubungkan dengan com. Berikut adalah hasil pengujian output:

Tabel 2: Pengujian Output

\begin{tabular}{|l|l|l|}
\hline Aksi & Reaksi & Hasil \\
\hline Com - R1 & Lampu 4 merah menyala (on) & Sesuai \\
\hline Com - R2 & Lampu 4 kuning menyala (on) & Sesuai \\
\hline Com - R3 & Lampu 4 hijau menyala (on) & Sesuai \\
\hline Com - R4 & Lampu 1 merah menyala (on) & Sesuai \\
\hline Com - R5 & Lampu 1 kuning menyala (on) & Sesuai \\
\hline Com - R6 & Lampu 1 hijau menyala (on) & Sesuai \\
\hline Com - R7 & Lampu 2 merah menyala (on) & Sesuai \\
\hline Com - R8 & Lampu 2 kuning menyala (on) & Sesuai \\
\hline Com - R9 & Lampu 2 hijau menyala (on) & Sesuai \\
\hline Com - R10 & Lampu 3 merah menyala (on) & Sesuai \\
\hline Com - R11 & Lampu 3 kuning menyala (on) & Sesuai \\
\hline Com - R12 & Lampu 3 hijau menyala (on) & Sesuai \\
\hline
\end{tabular}

*Sesuai: sesuai dengan kebenaran alat yang diuji

\section{Pengujian Perangkat Lunak}

Pengujian perangkat lunak ini merupakan pengujian program kontrol lampu rambu lalu lintas yang dibuat dalam bentuk ladder diagram. Pengujian tersebut dapat diuji benar tidaknya program apabila program tersebut dihubungkan dengan perangkat keras PLC Omron CPM1A. Hasil pengujian program diatas dapat dilihat pada tabel hasil pengujian di bawah ini:

Program bekerja secara manual (Auto-On)

Tabel 3: Pengujian program manual

\begin{tabular}{|c|c|c|c|}
\hline AKSI & REAKSI & HASIL & Keterangan \\
\hline - $\quad$ Auto on & - $\quad$ Auto1 on & Sesuai & $\begin{array}{ll}\text { - } & \text { Menunjukkan } \\
\text { lampu } \\
\text { indikator pada } \\
\text { posisi } \\
\text { menyala(on) }\end{array}$ \\
\hline $\begin{array}{l}\text { - L1 hijau on } \\
\text { selama } 100 \\
\text { detik }\end{array}$ & $\begin{array}{l}\text { - L3, L4, L2 merah } \\
\text { akan on dengan } \\
\text { waktu 110,220,330 } \\
\text { detik }\end{array}$ & Sesuai & 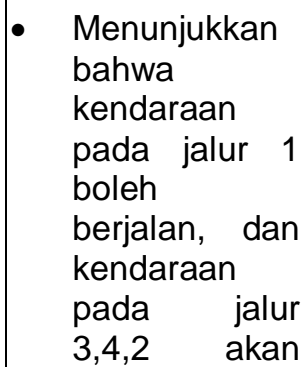 \\
\hline
\end{tabular}




\begin{tabular}{|c|c|c|c|}
\hline & & & berhenti \\
\hline $\begin{array}{l}\text { - L3 hijau on } \\
\text { selama } 100 \\
\text { detik }\end{array}$ & $\begin{array}{l}\text { - } \quad \text { L4, L2, L1 merah } \\
\text { akan on dengan } \\
\text { waktu 110,220,330 } \\
\text { detik }\end{array}$ & Sesuai & $\begin{array}{l}\text { - Menunjukkan } \\
\text { bahwa } \\
\text { kendaraan } \\
\text { pada jalur 3 } \\
\text { boleh } \\
\text { berjalan, dan } \\
\text { kendaraan } \\
\text { pada jalur } \\
1,4,2 \text { akan } \\
\text { berhenti }\end{array}$ \\
\hline $\begin{array}{l}\text { - L4 hijau on } \\
\text { selama } 100 \\
\text { detik }\end{array}$ & $\begin{array}{l}\text { - } L 2, L 1, L 3, \text { merah } \\
\text { akan on dengan } \\
\text { waktu 110,220,330 } \\
\text { detik. }\end{array}$ & Sesuai & 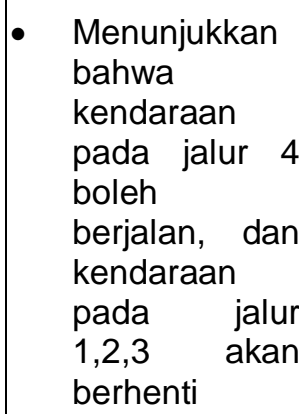 \\
\hline $\begin{array}{l}\text { - L2 hijau on } \\
\text { selama } 100 \\
\text { detik }\end{array}$ & $\begin{array}{l}\text { - L1, L3, L4, merah } \\
\text { akan on dengan } \\
\text { waktu,110,220,330 } \\
\text { detik }\end{array}$ & Sesuai & $\begin{array}{l}\text { - Menunjukkan } \\
\text { bahwa } \\
\text { kendaraan } \\
\text { pada jalur 2 } \\
\text { boleh } \\
\text { berjalan, dan } \\
\text { kendaraan } \\
\text { pada jalur } \\
1,3,4 \quad \text { akan } \\
\text { berhenti }\end{array}$ \\
\hline
\end{tabular}

Program bekerja secara Otomatis (Auto-On)

Tabel 4: Pengujian program otomatis

\begin{tabular}{|c|c|c|c|}
\hline AKSI & REAKSI & HASIL & Keterangan \\
\hline $\begin{array}{l}\text { - Bila } \\
\text { sensor } 1 \\
\text { bekerja }\end{array}$ & $\begin{array}{l}\text { - Auto } 2 \text { on } \\
\text { - L1 hijau on } \\
\text { dengan selang } \\
\text { waktu } 40 \text { detik } \\
\text { dan akan on }\end{array}$ & Sesuai & $\begin{array}{ll}\text { - } & \text { Menunjukkan } \\
\text { lampu indikator } \\
\text { pada posisi } \\
\text { menyala (On) } \\
\text { - Menunjukkan } \\
\text { bahwa } \\
\text { kendaraan } \\
\text { pada jalur 1 }\end{array}$ \\
\hline
\end{tabular}




\begin{tabular}{|c|c|c|}
\hline & $\begin{array}{l}\text { selama. Dan } \\
\text { L3,L4,L2 merah } \\
\text { akan on selama } \\
\text { kendaraan yang } \\
\text { melewati jalur1 } \\
\text { berkurang }\end{array}$ & $\begin{array}{l}\text { boleh berjalan, } \\
\text { dan kendaraan } \\
\text { pada jalur } 3,4,2 \\
\text { akan berhenti }\end{array}$ \\
\hline $\begin{array}{l}\text { - Bila } \\
\text { sensor } 2 \\
\text { bekerja }\end{array}$ & $\begin{array}{l}\text { - } \mathrm{L} 4 \text { hijau on } \\
\text { dengan selang } \\
\text { waktu } 40 \text { detik } \\
\text { dan L2,L3,L1 } \\
\text { merah akan on } \\
\text { selama } \\
\text { kendaraan yang } \\
\text { melewati jalur } 4 \\
\text { berkurang. }\end{array}$ & $\begin{array}{l}\text { - Menunjukkan } \\
\text { bahwa } \\
\text { kendaraan } \\
\text { pada jalur } 4 \\
\text { boleh berjalan, } \\
\text { dan kendaran } \\
\text { pada jalur } 2,3,1 \\
\text { akan berhenti }\end{array}$ \\
\hline
\end{tabular}

Diagram waktu penyalaan tiap fase dalam satu cycle adalah:

FASA 1

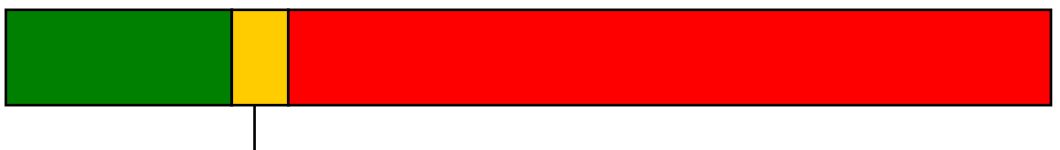

FASA 3

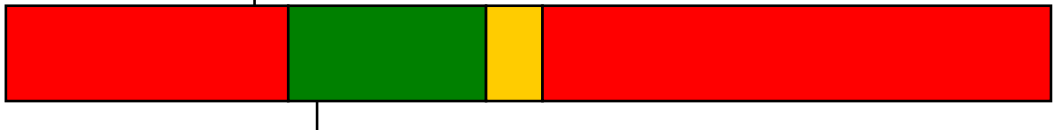

FASA 4

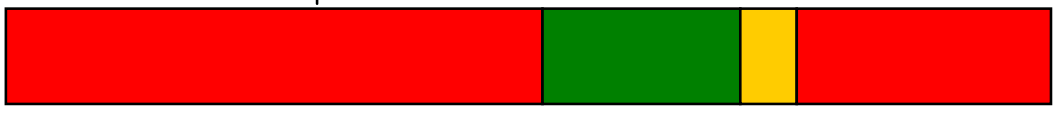

FASA 2

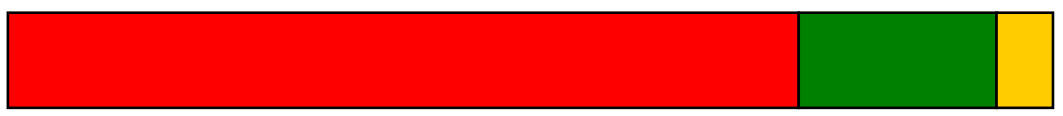

TIMER

Detik

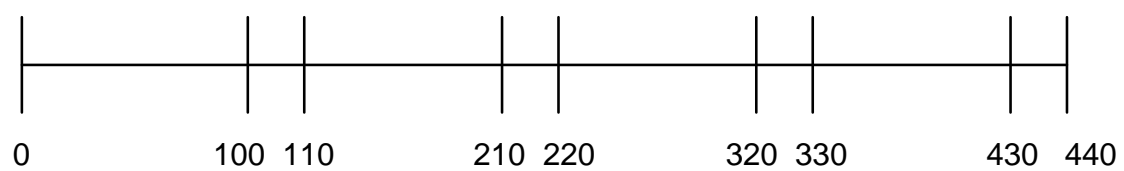

Keterangan:

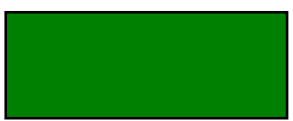

Hijau

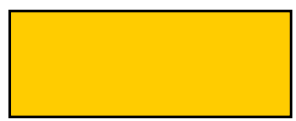

Kuning

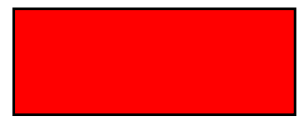

Merah 


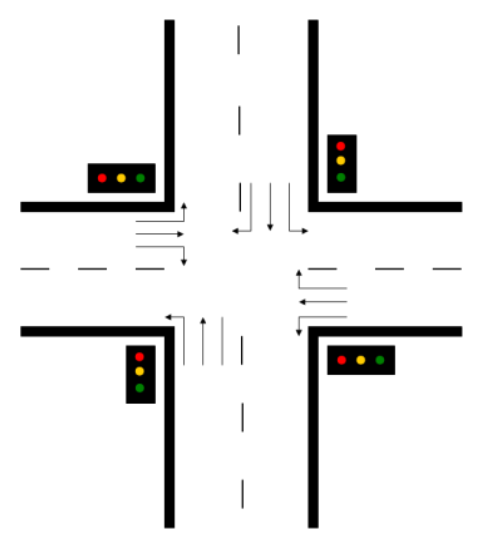

Gambar 1: Sistem Pengaturan Lampu Lalu Lintas di Simpang Empat
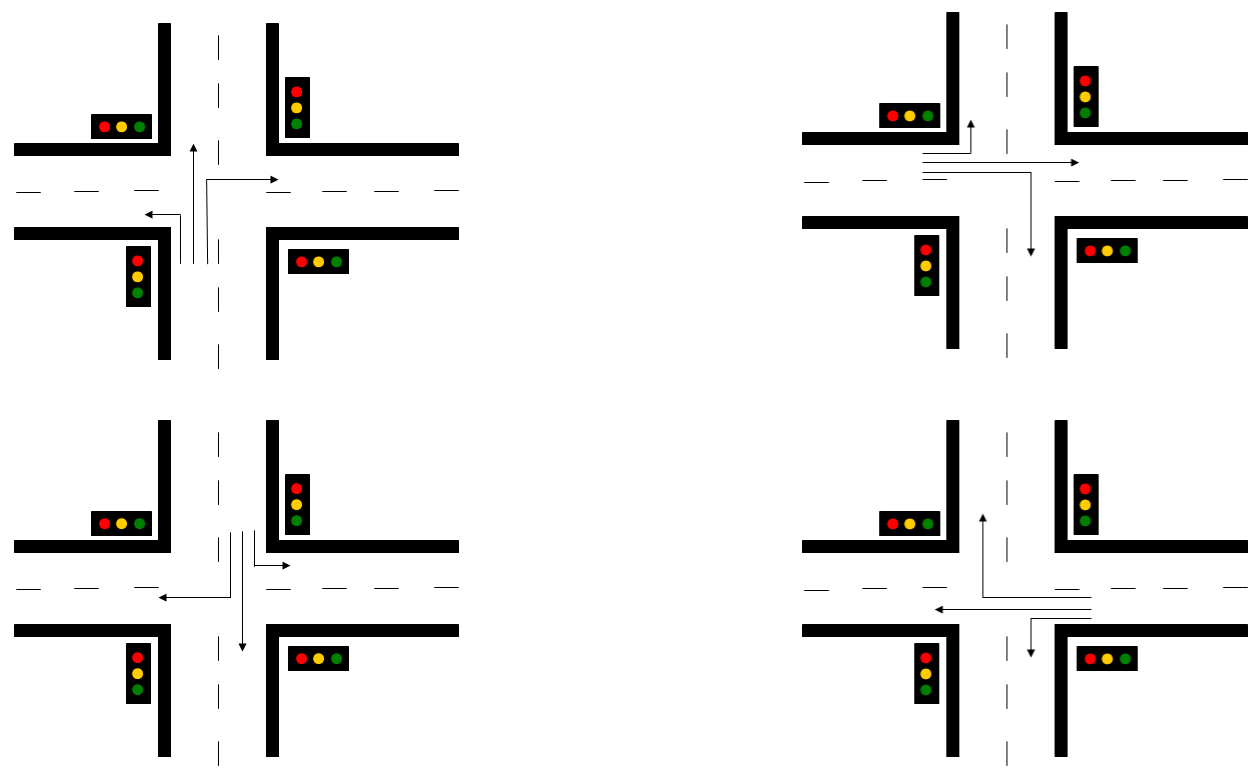

Gambar 2: Pergerakan Lampu Lalu Lintas Tiap Fase

Dari hasil pengujian perangkat lunak ini sesuai dengan kerja simulator kontrol lampu rambu lalu lintas dengan menggunakan program CX-Programmer berbasis PLC Omron CPM1A yang diaplikasikan untuk sistem kontrol lampu rambu lalu lintas pada simulator ini. Hasil yang diinginkan telah sesuai dengan kerja simulator yaitu pengujian program secara manual dan secara otomatis.

\section{Pelaksanaan Penyalaan Sinyal}

Untuk dapat menyalakan sinyal sinyal dalam suatu fasa dapat dilakukan sebagai berikut:

Ditentukannya sebuah referensi penyalaan yang berarti bahwa setiap sinyal warna hijau dapat melakukan penyalaan beberapa saat sesudah munculnya referensi. Untuk ini diambil besaran yang disebut set hijau $(\mathrm{SH})$, misalnya untuk fasa satu, maka ditulis $\mathrm{SH} 1$. 
a. Sinyal warna hijau menyala selama selang waktu yang telah ditentukan (LH) selama 100 detik.

b. Sinyal warna kuning akan menyala sesudah sinyal warna hijau selesai menyala. Sinyal warna kuning akan menyala selama (LK) satuan waktu yang ditentukan selama 10 detik.

c. Sinyal warna merah menyala setelah sinyal warna kuning selesai menyala, penghitungan lamanya sinyal merah menyala dari fase ke fase dapat dihitung memakai rumus dbawah ini:

Dimana $\mathrm{P}=$ waktu perioda

$$
\mathrm{LM}=\mathrm{P}-\mathrm{LH}-\mathrm{LK}
$$

$\mathrm{LH}=$ lampu hijau

LK = lampu kuning

$\mathrm{LM}=$ lamanya sinyal merah menyala

\section{Analisis}

Setelah melakukan pengujian pada perangkat keras dan perangkat lunak, penulis menyimpulkan bahwa simulator kontrol lampu rambu lalu lintas dengan PLC Omron CPM1A dapat bekerja dengan baik. Misalnya pada pendeteksian sensor untuk mendeteksi kepadatan atau kendaraan yang melintasi sensor dengan 12 kali percobaan 1 kali yang gagal, hal ini disebabkan ketidakpresisian sensor yang digunakan dan seting waktu pada program PLC maupun kesalahan mekanik lainnya, itu berarti tingkat kegagalannya adalah:

$$
\frac{1}{12} x 100 \%=8,33 \%
$$

Adapun tingkat keberhasilan dari simulator ini adalah:

$\frac{11}{12} \times 100 \%=91,66 \%$

Dengan perhitungan analisis diatas dapat disimpulkan bahwa tingkat persentasi kegagalan lebih kecil dibandingkan tingkat keberhasilan, oleh karena itu alat simulator yang dibuat ini bekerja dengan sempurna.

\section{PENUTUP}

Simpulan

Berdasarkan hasil pengujian dan data yang diperoleh, maka untuk RANCANG BANGUN SIMULATOR KONTROL LAMPU RAMBU LALU LINTAS BERBASIS PLC OMRON CPM1A dapat disimpulkan:

1. Fungsi rangkaian kontrol berjalan dengan baik dengan tingkat keberhasilan alat mencapai 91,66 $\%$.

2. Sensor ultrasonik yang digunakan tidak bekerja dengan sempurna, hal ini disebabkan untuk mendapatkan posisi yang tepat antara bagian pengirim dan penerima sangat sulit dan memerlukan sudut penerimaan dari sinar ultrasonik pada bagian penerima.

3. Bila sensor 1 dan 2 bekerja berbarengan atau terjadi samasama padat antara jalur 1 dan jalur 4, maka yang bekerja duluan adalah sensor 1, hal ini disebabkan settingan pada program PLC nya.

4. Sensitifitas sensor ultrasonik kurang berfungsi dengan baik dan rawan dari berbagai gangguan yang mungkin terjadi.

5. Kinerja dari sistem simulasi kontrol lampu rambu lalu lintas sangat 
dipengaruhi oleh sensitivitas dari sensor yang digunakan.

6. Simulator ini berhasil mendeteksi kendaraan yang melintasi sensor ultrasonik

\section{Saran}

1. Diharapkan untuk sensor pendeteksi kepadatan arus lalu lintas menggunakan sensor yang mendeteksi bahan logam, agar pendeteksi kepadatan arus lalu lintas bekerja untuk bahan-bahan dari logam saja seperti mobil, motor, dan kendaraan lainnya.

2. Untuk pengembangan lebih lanjut diharapkan dalam pembuatan simulator agar lebih komplek.

3. Ketelitian dalam pemasangan instalasi rangkaian kontrol sangat diperlukan agar tidak mengalami kesulitan terutama dalam melakukan pengujian rangkaian kontrol yang ada pada simulator tersebut.

4. Dalam penempatan komponen untuk simulasi ini agar lebih diperhatikan agar dapat menambah estetika (keindahan).

5. Bila sistem suatu alat ini diterapkan sebagai pengaturan lampu lalu lintas sebenarnya, maka perlu penelitian lebih lanjut dilapangan.

\section{DAFTAR PUSTAKA}

Drs. Sumanto, MA, 1995, Mesin Arus Searah, Andi Offset Yogyakarta.

Jhon W.W, 1999, Programmer Logic Controllers, Fourth Edition Prentice Hall, New Jersey.

M.Budiyanto, A. Wijaya, (2006), Pengenalan Dasar - Dasar Pemograman Logic
Controller dan Aplikasi, Yogyakarta: GAVA MEDIA.

Omron (1996), Buku Petunjuk Pemakaian PLC Omron jenis CPM1, Jakarta.

P.Van.Harten, Ir.E.Setiawan, 1974 Instalasi Arus Kuat 1. Nederland.

P.Van.Harten, Ir.E.Setiawan, 1974 Instalasi Arus Kuat 2. Nederland.

P.Van.Harten, Ir.E.Setiawan, 1974 Instalasi Arus Kuat 3. Nederland.

W.Bolton, 2004, Programmer Logic Controller, Edition 3, W.Bolton. 